\title{
Multi-walled carbon nanotubes as secondary fibre fillers for property improvement of short carbon fibre-reinforced silicone rubber
}

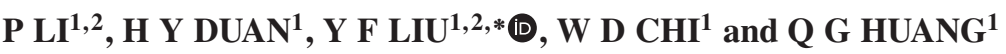 \\ ${ }^{1}$ Key Laboratory of Beijing City on Preparation and Processing of Novel Polymer Materials, Beijing University of \\ Chemical Technology, Beijing 100029, People's Republic of China \\ ${ }^{2}$ Beijing Key Laboratory of Advanced Functional Polymer Composites, Beijing University of Chemical Technology, \\ Beijing 100029, People's Republic of China \\ *Author for correspondence (liuyunfang@ mail.buct.edu.cn)
}

MS received 29 May 2018; accepted 4 March 2019; published online 30 May 2019

\begin{abstract}
To improve the properties of room temperature vulcanized (RTV) silicone rubber, functional multi-walled carbon nanotubes (MWCNTs) and short carbon fibres were added into the RTV silicone rubber as hybrid fibre fillers. The functionalized MWCNTs were characterized by transmission electron microscopy and X-ray photoelectron spectroscopy. The mechanical, thermal and ablative properties of the fabricated RTV silicone rubber composites were investigated. Their properties were enhanced by adding the functionalized MWCNTs with appropriate contents. The tensile strength and tear strength of the composites are improved from 4.0 MPa and $20.3 \mathrm{kN} \mathrm{m}^{-1}$ to $4.3 \mathrm{MPa}$ and $21.3 \mathrm{kN} \mathrm{m}^{-1}$, respectively, when the MWCNT content increased from 0 to $0.5 \mathrm{phr}$. In addition, the decomposition temperatures at the onset point and $50 \%$ mass loss increased from 493.4 and $564.4^{\circ} \mathrm{C}$ to 498.8 and $612.4^{\circ} \mathrm{C}$, respectively. The mass and line ablation rates also decreased from $0.062 \mathrm{~g} \mathrm{~s}^{-1}$ and $0.148 \mathrm{~mm} \mathrm{~s}^{-1}$ to $0.059 \mathrm{~g} \mathrm{~s}^{-1}$ and $0.145 \mathrm{~mm} \mathrm{~s}^{-1}$, respectively.
\end{abstract}

Keywords. Multi-walled carbon nanotubes; silicone rubber; carbon fibres; mechanical properties; thermal properties.

\section{Introduction}

The use of hybrid fillers in polymer-based composites is an effective method to synergistically improve the properties of the final hybrid materials [1-3]. The used fillers could be polymers or inorganic materials with different dimensions (0-, 1-, 2- and 3-dimensional) or various sizes (nanoscale, microscale and even macroscale). Fibre materials are very important fillers for composites due to their special structures and properties, such as aramid fibres [4], glass fibres [4], carbon fibres (CFs) [4,5] and carbon nanotubes (CNTs) [1-3,5-10].

Room temperature vulcanized (RTV) silicone rubber as a special elastomer has many excellent properties, such as high abrasion resistance, good heat stability, low flammability and facile processability [11-13]. Therefore, RTV silicone rubber has widely been used in aerospace, building, automotive, shipbuilding, healthcare, chemicals, petrochemical fields and so on [11-13]. For example, Seyedmehdi et al [14] used the RTV silicone rubber for high-performance insulator coating due to its excellent superhydrophobic properties. Siderakis and Agoris [15] introduced the performance of RTV silicone rubber for outdoor insulator coating.

To improve the properties of RTV silicone rubber, many fillers with different scales have widely been used such as CNTs, CFs, graphene, silica nanoparticles and montmorillonite [5,6,11,13,16-19] and the nanoscale materials especially deserve our attention. By using nanoscale fillers, several benefits may be achieved: (1) assisting the main filler to improve the composite properties, (2) providing some new properties for the composite, (3) improving the compatibility between the polymer matrix and the filler and (4) synergistically promoting the filler dispersion in the matrix.

CNTs could be many kinds of promising multifunctional fillers for polymer composites due to their special structure and excellent properties. Previously, CNTs have especially attracted a great deal of interest in rubbers/elastomers as multifunctional fillers to improve the mechanical, thermal, electrical and ablation properties of the fabricated composites [20-23] and much progress has been achieved. In our previous studies, the modified short carbon fibres (SCFs) or multi-walled carbon nanotubes (MWCNTs) as fibre fillers were separately used with $\mathrm{SiO}_{2}$ particles [5,6]. When the silica content exceeds $10 \mathrm{phr}$ or the fibre filler (SCFs or MWCNTs) content exceeds $4 \mathrm{phr}$, the processability significantly becomes worse and the filler dispersion is worsened. As a result, the properties of the RTV silicone rubber composites will degrade. Compared with the addition of MWCNTs, the RTV silicone rubber composites have higher mechanical and thermal properties when the SCFs are used. Therefore, how to further improve the properties of the RTV silicone rubber 
composite with good processability becomes a challenge. The use of multiscale fibre fillers (nanoscale and microscale) enables the composites with improved properties due to their synergistic effects. In this paper, two functional fibre fillers with different scales (MWCNTs and SCFs) were utilized with silica fillers to improve the properties of the reinforced RTV silicone rubber composites. The effects of the MWCNT content on the mechanical, thermal and ablation properties of the composites were investigated. The morphologies and compositions of the ablated surface and the longitudinal section of the RTV silicone rubber composite were also studied.

\section{Experimental}

\subsection{Materials and methods}

RTV silicone (107\#), 3-aminopropyltriethoxysilane (KH550), tetraethyl orthosilicate (TEOS) and dibutyltin dilaurate (DBTDL) were manufactured by Shanghai Resin Factory Co. Ltd. Fumed silica (AS-380) was purchased from Shenyang Chemical Co. Ltd. Concentrated $\mathrm{HNO}_{3}\left(14.4 \mathrm{~mol} \mathrm{l^{-1 }}\right)$ and petroleum ether were produced by Sinopharm Chemical Reagent Beijing Co. Ltd. $\mathrm{Fe}_{2} \mathrm{O}_{3}$ powder was bought from Nanjing Haitai Nanomaterials Co. Ltd. SCFs were bought from Lanzhou Carbon Co. Ltd. The diameter and length of the SCFs are about 7-12 $\mu \mathrm{m}$ and 4-20 mm, respectively. The MWCNTs were prepared by an ultrasonic-spray catalytic pyrolysis in a vertical furnace [24]. The ultrasonic spray nozzle (G40 M) was bought from Siansonic Technology Ltd.

\subsection{Treatment of SCFs and MWCNTs}

As we know, the compatibility of the filler with matrix strongly depends on the surface properties of the filler and the polarity of the rubber matrix. So the SCFs and MWCNTs were first treated by a combination method before use. The detailed treatment process is as follows: (1) SCFs or MWCNTs were treated with concentrated $\mathrm{HNO}_{3}$ ( $\mathrm{m}(\mathrm{SCF}$ or MWCNTs): $\left.\mathrm{V}\left(\mathrm{HNO}_{3}\right)=1 \mathrm{~g}: 50 \mathrm{ml}\right)$ at $90^{\circ} \mathrm{C}$ for $2 \mathrm{~h}$, (2) the above mixture was filtered, washed with deionized water and anhydrous ethanol and then dried, (3) the sample was further dipped in the KH550 aqueous solution (2\%) for $4 \mathrm{~h}$ and (4) the above treated SCFs or MWCNTs were washed with deionized water and anhydrous ethanol several times and dried for the use.

\subsection{Preparation of silicone rubber composites}

The RTV silicone rubber composites were fabricated as follows: (1) silicone rubber was dissolved in petroleum ether to obtain a homogeneous solution, (2) fumed silica (10 parts per hundreds of rubber (phr)), KH550 (1 phr) and water (0.25 phr) were added to the above solution and agitated for $2 \mathrm{~h}$ after ultrasonic treatment (30 min), (3) $\mathrm{Fe}_{2} \mathrm{O}_{3}$ (4 phr) was mixed with the above mixture by agitation, (4) the treated MWCNTs were added into the above mixture and ultrasonically treated for $30 \mathrm{~min}$ and further agitated for $1 \mathrm{~h},(5)$ the treated SCFs (4 phr) were added into the above mixture by ultrasonic treatment (30 min) and further agitated for $2 \mathrm{~h},(6)$ the mixture was desolventized in a vacuum oven at $50^{\circ} \mathrm{C}$ and (7) then, the curing agent and catalyst (TEOS and DBTDL) were added into the mixture with stirring and further moved into a mould for curing to obtain RTV rubber composites.

\subsection{Characterization}

The structures and surface properties of the MWCNTs were characterized by using a transmission electron microscopy (TEM, FEI, Tecnai-G20) and X-ray photoelectron spectroscopy analysers (XPS, Perkin-2-Elmer PHI-5300). The microstructure of the SCFs, the fractured surfaces of the RTV silicone rubber composites and the corresponding surface and longitudinal section after ablation were observed by using a scanning electron microscope (SEM, Hitachi S4700, Japan).

The mechanical properties of the composites were determined using a universal testing machine (CMT24204, USA) at room temperature. The measurement conditions conform to the Chinese national standard GB/T528-2009 and GB/T5292008. Hardness (Shore A) was measured using a Shore A durometer (XHS, Yingkoushi Material Tester Co., China) according to the Chinese national standard GB/T531.1-2008. And more than five samples were measured for each property testing. The thermogravimetric (TG) analysis was performed using a Netzsch Instrument (TG 209 F3 Tarsus). The composite samples were heated from ambient temperature to $700^{\circ} \mathrm{C}$ at a heating rate of $10 \mathrm{~K} \mathrm{~min}^{-1}$ in an air atmosphere. Ablation testing was performed on an oxy-acetylene ablation tester (YS-2, Xian Tianguan Sci. Co. Ltd., China). The test conditions were as follows: flow velocities of $\mathrm{O}_{2}$ and $\mathrm{C}_{2} \mathrm{H}_{2}$, $0.35 \mathrm{~m}^{3} \mathrm{~h}^{-1}$ and $0.35 \mathrm{~m}^{3} \mathrm{~h}^{-1}$; vertical distance between the nozzle and sample surface, $10 \mathrm{~mm}$; diameter of nozzle, $2 \mathrm{~mm}$; temperature of oxy-acetylene flame, $>2000^{\circ} \mathrm{C}$ and testing time, $20 \mathrm{~s}$. The linear ablation rate $\left(R_{1}\right)$ and mass ablation rate $\left(R_{\mathrm{m}}\right)$ were calculated by equations (1) and (2), respectively:

$$
\begin{aligned}
R_{1} & =\left(h_{0}-h\right) / t, \\
R_{\mathrm{m}} & =\left(m_{0}-m\right) / t,
\end{aligned}
$$

where $h_{0}$ and $h$ are the height of the sample before and after ablation, respectively, $m_{0}$ and $m$ are the mass of the sample before and after ablation, respectively, and $t$ is the ablation time (20 s).

\section{Results}

\subsection{Characterization of SCFs and MWCNTs}

It is well known that the surface state of the filler is one of the key factors affecting the properties of the fabricated 

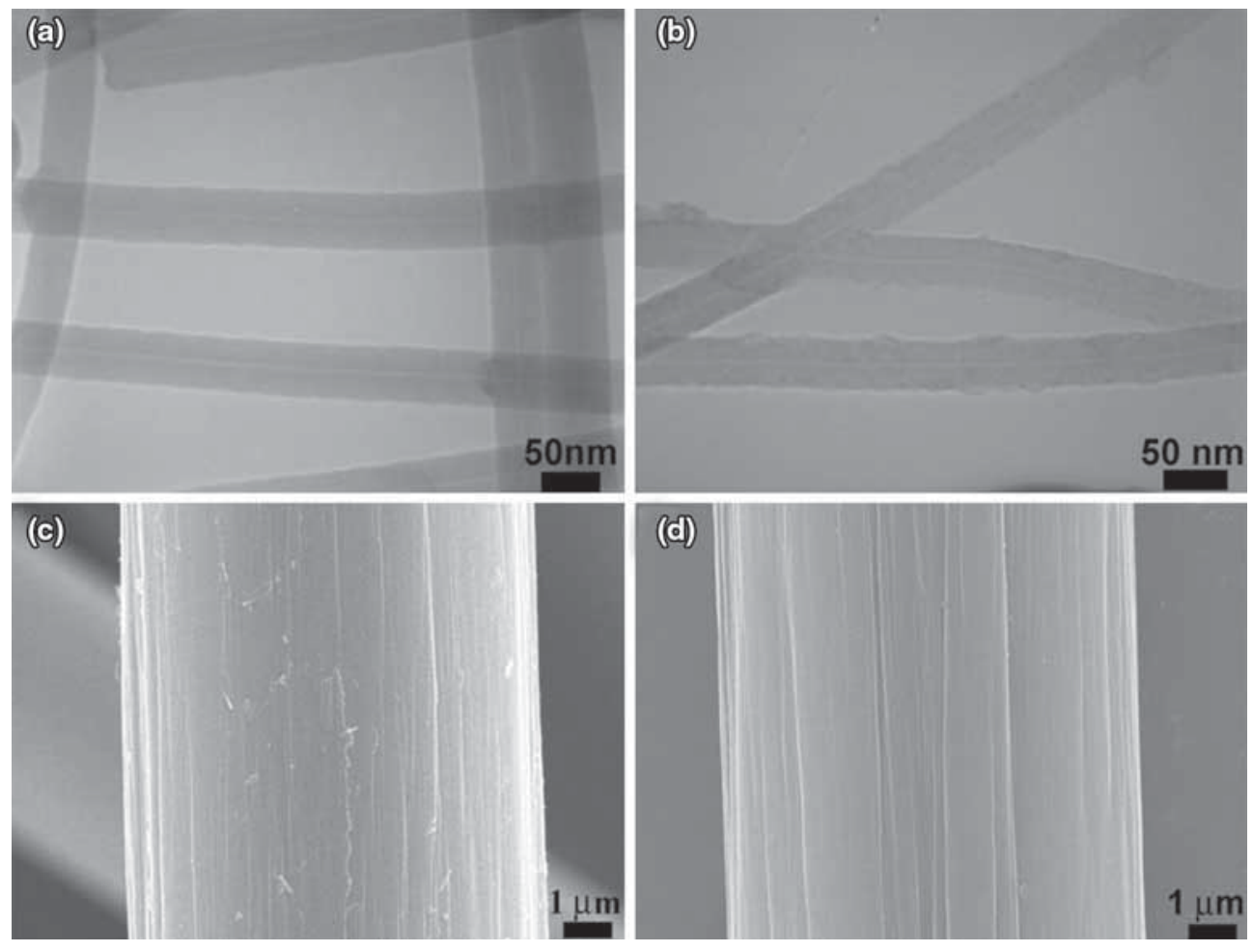

Figure 1. TEM images of MWCNTs: (a) raw and (b) after acid-KH550 treatment, and SEM images of SCFs: (c) raw and (d) after acid-KH550 treatment.

composites. Therefore, both fillers (SCFs and MWCNTs) should be modified before use by different methods according to the used resin. Previous studies have confirmed that the properties of the RTV silicone rubber composites by adding untreated SCFs or CNTs are obviously worse than that of the composites with functionalized fillers $[5,6]$. The acidKH550 treatment is a very effective modification method for MWCNTs. The grafted KH550 molecules will improve the interfacial compatibility between the fillers and RTV silicone rubber matrix.

Figure 1 shows the TEM images of the MWCNTs and SEM images of the SCFs before and after acid-KH550 treatment. The raw MWCNTs have a straight morphology with the diameter in the range of $40-90 \mathrm{~nm}$. The length of the MWCNTs is longer than $10 \mu \mathrm{m}$. Compared with the raw sample, the acidKH550-treated MWCNTs have a relatively coarser surface due to the acid oxidation. The diameters of the SCFs are in the range of $7-12 \mu \mathrm{m}$. It can be found that the SCFs have a typical trench-structure of CFs [25-27]. But the trench of the treated SCFs is relatively deeper than that of the untreated sample. The modified surface states of the MWCNTs and SCFs will be in favour of the improvement of the interaction between fillers and the matrix. The XPS data of the MWCNTs and SCFs are shown in table 1. The silicone and oxygen contents of the raw SCFs are about 1.7 and $13.7 \mathrm{wt} . \%$, respectively. These two elements originate from the oil and sizing agents used in the production process of CFs. After treatment, the contents of the oxygen, nitrogen and all silicon elements
Table 1. XPS data of SCFs and MWCNTs before and after acid-KH550 treatment.

\begin{tabular}{lcrrr}
\hline & \multicolumn{4}{c}{ Content (at.\%) } \\
\cline { 2 - 5 } Element sample & $\mathrm{C}$ & $\mathrm{O}$ & $\mathrm{N}$ & $\mathrm{Si}$ \\
\hline Raw SCFs & 83.02 & 13.67 & 1.66 & 1.65 \\
Treated SCFs & 74.99 & 18.94 & 2.71 & 3.36 \\
Raw MWCNTs & 92.32 & 6.84 & 0.45 & 0.39 \\
Treated MWCNTs & 87.40 & 9.07 & 1.42 & 2.11 \\
\hline
\end{tabular}

in the MWCNTs and SCFs will increase. The data prove the successful grafting of the KH550 molecules on the surface of the MWCNTs and SCFs. The modified surface chemical states of the MWCNTs and SCFs will contribute to the compatibility improvement between the fillers and the silicone rubber matrix.

\subsection{Mechanical properties of RTV silicone rubber composites}

Figure 2 shows the mechanical properties of the MWCNT/ SCF-enhanced RTV silicone rubber composites with different MWCNT contents. The tensile strength and tear strength of the composite without adding MWCNTs are about $4.0 \mathrm{MPa}$ and $20.3 \mathrm{kN} \mathrm{m}^{-1}$, respectively. After adding MWCNTs, it is 

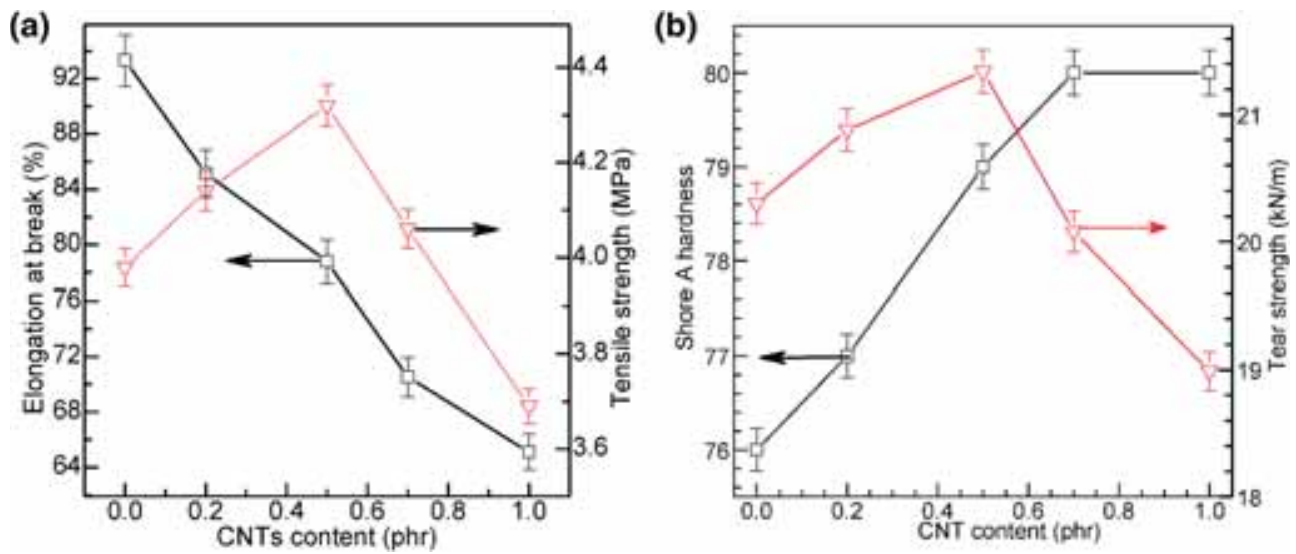

Figure 2. (a) Tensile strength and elongation at break and (b) Shore A hardness and tear strength of RTV silicone rubber composites with different MWCNT contents.

found that the tensile and tear strengths of the composites improved with an increase in the MWCNT content and reach the maximum values at $0.5 \mathrm{phr}$ of the MWCNT content. The corresponding tensile and tear strengths are respectively about 4.3 $\mathrm{MPa}$ and $21.3 \mathrm{kN} \mathrm{m}^{-1}$. The elongation decreases and Shore A hardness increased with an increase in the MWCNT content in the composites. The MWCNTs will have a good compatibility and strong binding strength with the silicone rubber matrix after $\mathrm{HNO}_{3}$ oxidation and KH550 grafting. At a relatively low content, the MWCNTs could have a good dispersion in the silicone rubber matrix. When a relatively higher MWCNT content is used, the viscosity of the mixture in the composite fabrication process obviously becomes high. So, it is unavoidable that the high viscosity will decrease the MWCNT dispersion in the matrix. The MWCNT aggregates will inevitably impair the properties of the composites [28-30].

Figure 3 shows the SEM images of the fracture faces of MWCNT/SCF-enhanced RTV silicone rubber composites. It is clear that the SCFs are coated with the rubber matrix when the MWCNT content is not $>0.7 \mathrm{phr}$. This phenomenon is more obvious in the composite with $0.5 \mathrm{phr}$ of MWCNTs as shown in figure $3 \mathrm{~d}$. For the composite with $1 \mathrm{phr}$ of MWCNTs, only a few residual rubber matrices could be found on the SCFs. The results clearly demonstrate that an appropriate MWCNT content contributes to the improvement in the bonding properties between the SCFs and silicone rubber. A high MWCNT content will lead to the aggregation of MWCNTs and bad dispersion of the fillers $\left(\mathrm{SiO}_{2}, \mathrm{SCFs}\right.$, MWCNTs and $\mathrm{Fe}_{2} \mathrm{O}_{3}$ ) in the rubber matrix, which deteriorate the binding between the fillers and matrix and form some defects. This is the cause for the decreased mechanical properties.

\subsection{Thermal properties of RTV silicone rubber composites}

Figure 4 and table 2 show the thermal analysis results of the SCF-enhanced RTV silicone composites with different MWCNT contents. For the RTV silicone composite without the addition of MWCNTs, the onset decomposition temperature $\left(T_{\mathrm{d}}\right)$ and the temperature at $50 \%$ mass loss $\left(T_{50}\right)$ are about 493.4 and $564.4^{\circ} \mathrm{C}$, respectively. And it is clear that this sample has only one decomposition temperature at the maximum mass loss rate $\left(T_{\mathrm{m}}\right)$, which is about $565.0^{\circ} \mathrm{C}$. The $T_{\mathrm{d}}$ and $T_{50}$ values increased with an increase in the MWCNT content in the composite and reached the maximum values at $0.5 \mathrm{phr}$ of the MWCNT content. For the composite with $0.5 \mathrm{phr}$ of MWCNT, the $T_{\mathrm{d}}$ and $T_{50}$ are 498.8 and $612.4^{\circ} \mathrm{C}$, respectively. The $T_{50}$ value shows a great increase compared with that of the composite without MWCNTs. But the $T_{50}$ value of the composite with $1 \mathrm{phr}$ of MWCNTs decreased to only $557.5^{\circ} \mathrm{C}$. It is clear from the differential thermogravimetric (DTG) curves that two decomposition temperatures at a maximum mass loss rate $\left(T_{\mathrm{m}}\right)$ appear for the composite having MWCNTs. It may be due to the existence of two kinds of carbon materials (SCFs and MWCNTs) in the composites. The single $T_{\mathrm{m}}$ of the RTV silicone rubber composite without MWCNT is only $565.0^{\circ} \mathrm{C}$. But the $T_{\mathrm{m}}^{1}$ and $T_{\mathrm{m}}^{2}$ values of the composite with $0.5 \mathrm{phr}$ of MWCNT are 575.7 and $660.9^{\circ} \mathrm{C}$, respectively. The results show the improvement in the thermal properties of the composite due to the synergistic effect between SCFs and MWCNTs. But when the MWCNT content is $1 \mathrm{phr}$, the peak of $T_{\mathrm{m}}^{2}$ almost disappears. It is possible due to the bad dispersion of the MWCNTs in the composite.

\subsection{Ablation properties of RTV silicone rubber composites}

Table 3 lists the ablation rates of the RTV silicone rubber composites. The mass and line ablation rates $\left(R_{\mathrm{m}}\right.$ and $\left.R_{\mathrm{d}}\right)$ of the RTV silicone rubber composites without MWCNTs are about $0.062 \mathrm{~g} \mathrm{~s}^{-1}$ and $0.148 \mathrm{~mm} \mathrm{~s}^{-1}$, respectively. The $R_{\mathrm{m}}$ and $R_{\mathrm{d}}$ values of the composites with $0.5 \mathrm{phr}$ of MWCNTs decreased to $0.059 \mathrm{~g} \mathrm{~s}^{-1}$ and $0.145 \mathrm{~mm} \mathrm{~s}^{-1}$, respectively. After adding $1 \mathrm{phr}$ of MWCNTs in the RTV silicone composite, the $R_{\mathrm{m}}$ and $R_{\mathrm{d}}$ values increased to $0.063 \mathrm{~g} \mathrm{~s}^{-1}$ and $0.150 \mathrm{~mm} \mathrm{~s}^{-1}$, respectively. The values are even larger than those of the composites without MWCNTs. The reason may originate from the defects in the composites caused by MWCNT aggregates. 

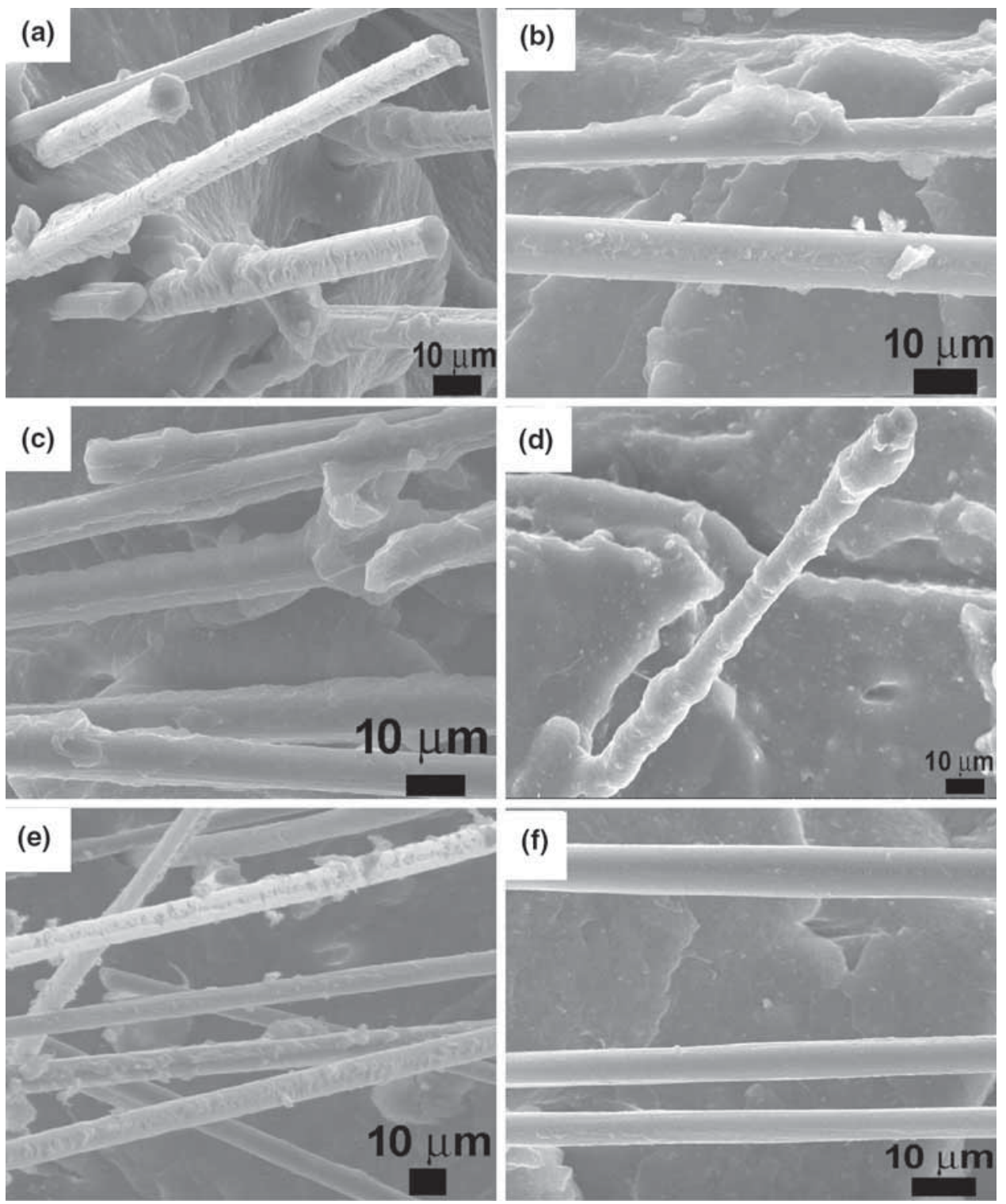

Figure 3. SEM images of fracture face of RTV silicone rubber composites with different MWCNT contents with (a) 0 , (b) 0.2 , (c) and (d) 0.5 , (e) 0.7 and (f) 1 phr.

These results make clear that appropriate MWCNT contents and good dispersion contribute to the improvement in the ablation properties of the composites.

Since the composite with $0.5 \mathrm{phr}$ of MWCNTs has relatively better ablation properties, their microstructures and compositions after ablation were further observed. The ablated surface layer of the composite (figure $5 b$ ) has a dense structure without obvious pores that is likely beneficial to resist the infiltration of the hot gas flow [5,31,32]. From the SEM observation of the longitudinal section of the ablated composite (figure 6a), a multilayer ablated structure could be found. Four layers could be approximately divided: virgin layer, pyrolysis layer, porous layer and dense layer [5,31-33]. Their corresponding EDS data are listed in table 4. From the inner to dense layer, the Si and Fe contents decreased gradually. For the virgin layer, the atom contents of the carbon, oxygen and silicon elements are about 57, 20 and 22 at.\%, respectively. The pyrolysis layer has a loose structure due to the degradation of the RTV silicone rubber and the release of decomposed products. The pyrolysis process will absorb the heat to protect the inner rubber matrix. The oxygen content in this layer decreases compared with the virgin layer that may be due to the formation and release of the oxygen-containing small molecules. The porous layer presents a porous structure and the SCFs and MWCNTs assist in supporting this layer as the structural framework. The carbon content (about 75.8 at.\%) in this layer increases outstandingly compared to the virgin and pyrolysis layers (57.1 and 55.2 at.\%); furthermore, 

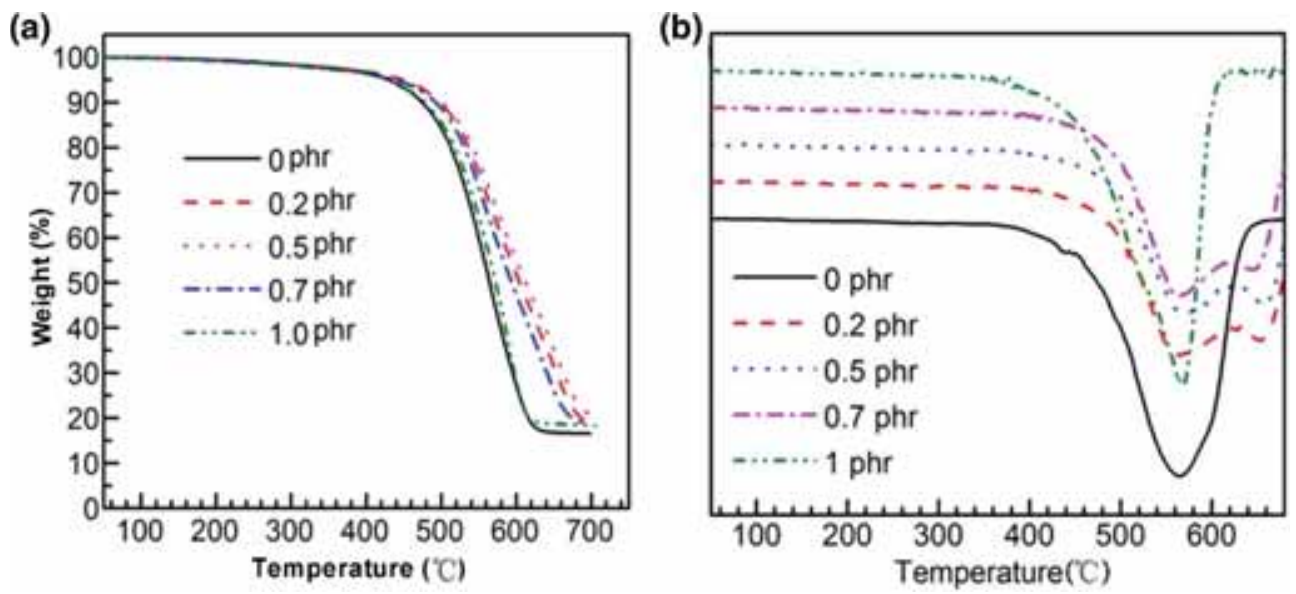

Figure 4. (a) TG and (b) DTG curves of RTV silicone rubber with different MWCNT contents.

Table 2. TG and DTG data of RTV silicone rubber composites.

\begin{tabular}{|c|c|c|c|c|c|c|}
\hline CNT content (phr) & $T_{5}\left({ }^{\circ} \mathrm{C}\right)$ & $T_{10}\left({ }^{\circ} \mathrm{C}\right)$ & $T_{50}\left({ }^{\circ} \mathrm{C}\right)$ & $T_{\mathrm{d}}\left({ }^{\circ} \mathrm{C}\right)$ & $T_{\mathrm{m}}^{1}\left({ }^{\circ} \mathrm{C}\right)$ & $T_{\mathrm{m}}^{2}\left({ }^{\circ} \mathrm{C}\right)$ \\
\hline 0 & 429.7 & 474.6 & 564.4 & 493.4 & 565.0 & - \\
\hline 0.2 & 448.0 & 498.8 & 604.3 & 493.9 & 565.4 & 651.0 \\
\hline 0.5 & 440.5 & 500.1 & 612.4 & 498.8 & 575.7 & 660.9 \\
\hline 0.7 & 437.7 & 492.6 & 593.9 & 494.8 & 564.7 & 645.3 \\
\hline 1 & 427.7 & 478.4 & 557.5 & 493.8 & 578.4 & 584.0 \\
\hline
\end{tabular}

$T_{5}$ : decomposition temperature at $5 \%$ mass loss; $T_{10}$ : decomposition temperature at $10 \%$ mass loss; $T_{50}$ : decomposition temperature at $50 \%$ mass loss; $T_{\mathrm{d}}$ : onset decomposition temperature; $T_{\mathrm{m}}^{1}$ : decomposition temperature at the first maximum mass loss rate and $T_{\mathrm{m}}^{2}$ : decomposition temperature at the second maximum mass loss rate.

Table 3. Ablation rates of RTV silicone rubber with different MWCNT contents.

\begin{tabular}{lcc}
\hline CNT contents $(\mathrm{phr})$ & $R_{\mathrm{m}}\left(\mathrm{g} \mathrm{s}^{-1}\right)$ & $R_{\mathrm{d}}\left(\mathrm{mm} \mathrm{s}^{-1}\right)$ \\
\hline 0 & 0.062 & 0.148 \\
0.2 & 0.061 & 0.147 \\
0.5 & 0.059 & 0.145 \\
0.7 & 0.060 & 0.147 \\
1 & 0.063 & 0.150 \\
\hline
\end{tabular}

the oxygen content reduces to only 8.7 at.\%. The possible reasons may be as follows: (1) carbonization of the RTV silicone rubber, (2) transformation into carbon of pyrolysis products diffused from the pyrolysis layer, (3) building of the porous framework by SCFs, MWCNTs and carbonized products and (4) the release of small molecules $\left(\mathrm{SiO}_{2}, \mathrm{CO}\right.$, $\mathrm{CO}_{2}$ and $\mathrm{H}_{2} \mathrm{O}$ ). The porous layer plays an important role in resisting the ablation by: (1) supporting the dense ablated layer, (2) absorbing heat, (3) preventing heat diffusion to the interior layer and (4) transferring the decomposed products
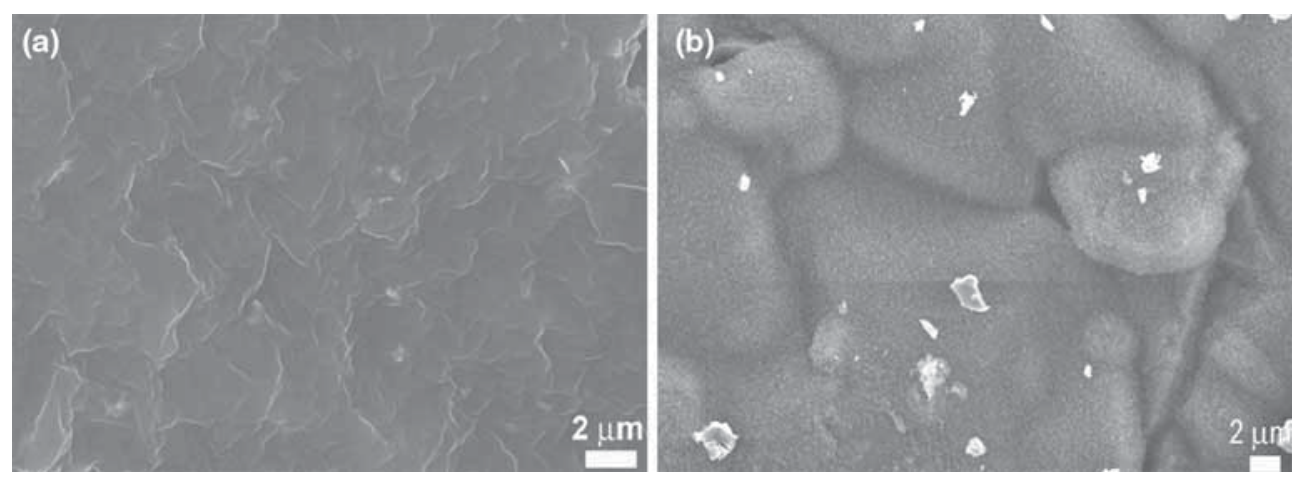

Figure 5. SEM images of the surface of RTV silicone rubber with $0.5 \mathrm{phr}$ of MWCNTs (a) before and (b) after ablation. 

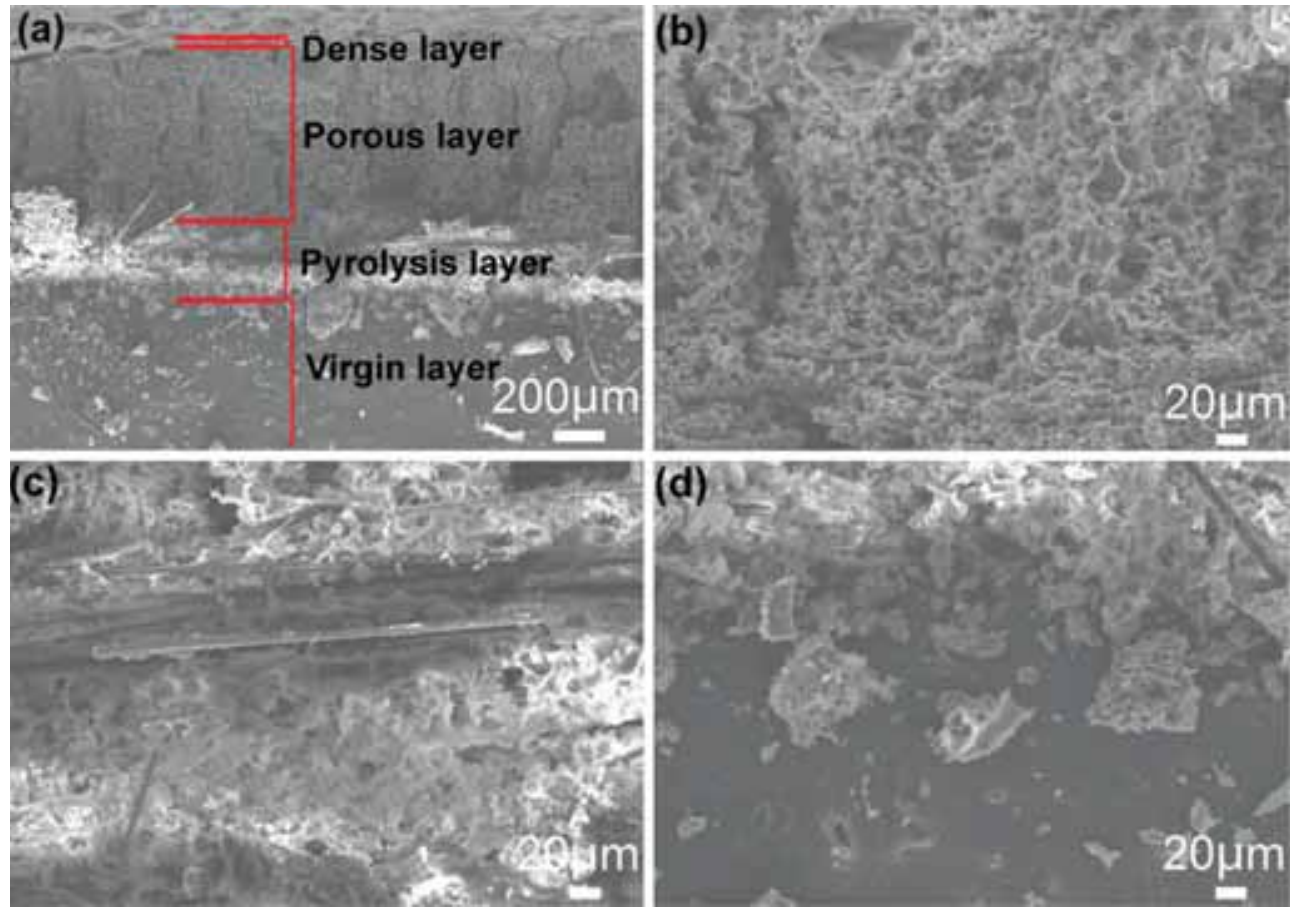

Figure 6. SEM images of RTV silicone rubber with $0.5 \mathrm{phr}$ of MWCNTs after ablation (a) section surface, (b) porous layer, (c) pyrolysis layer and (d) virgin layer.

Table 4. Ablation rates of RTV silicone rubber with different MWCNT contents.

\begin{tabular}{lrrrr}
\hline & \multicolumn{4}{c}{ Content (at.\%) } \\
\cline { 2 - 5 } Element part & $\mathrm{C}$ & \multicolumn{1}{c}{$\mathrm{O}$} & $\mathrm{Si}$ & $\mathrm{Fe}$ \\
\hline Virgin layer & 57.06 & 20.07 & 22.23 & 0.64 \\
Pyrolysis layer & 55.16 & 27.30 & 17.06 & 0.48 \\
Porous layer & 75.79 & 8.72 & 15.16 & 0.33 \\
Dense layer & 80.41 & 14.18 & 5.33 & 0.08 \\
\hline
\end{tabular}

outwardly. The MWCNTs with a large aspect ratio and good dispersion in the silicone rubber matrix could effectively assist in setting the porous layer with the SCFs and carbonization of RTV silicone. Furthermore, the MWCNTs have an excellent thermal conductivity, so the fast heat conduction could prevent local damage of the porous layer. The well bonding of the MWCNTs with the silicone matrix and SCFs will also be in favour of the strength improvement of the porous layer. The ablated layer has a relatively dense structure with about 80.4 at. \% of carbon content and only 5.3 at.\% of silicon content. The $\mathrm{SiO}_{2}$ material was liquefied and blown off under hot gas flow. This layer has a relatively higher oxygen content compared with the porous layer, which attributes to the formation of oxygen-containing functions. The importance of this layer is reflected in several ways: (1) hindering the diffusion of oxidizing compositions into the inner layers, (2) delaying the release of the decomposed products and prompting the carbonization, (3) absorbing heat due to liquefaction and gasification and (4) improving the anti-gas erosion ability.

\section{Conclusion}

In conclusion, we prepared the MWCNT/SCF-reinforced silicone rubber composites and investigated the effects of the MWCNT content on their mechanical, thermal and ablation properties. The RTV silicone rubber composite has relatively better properties when the MWCNT content is about 0.5 phr. The tensile and tear strengths of the composites are about $4.3 \mathrm{MPa}$ and $21.3 \mathrm{kN} \mathrm{m}^{-1}$, respectively. In addition, the onset decomposition temperature has also improved from 493.4 to $498.8^{\circ} \mathrm{C}$. The mass and line ablation rates of the RTV silicone rubber composites decreased to $0.059 \mathrm{~g} \mathrm{~s}^{-1}$ and $0.145 \mathrm{~mm} \mathrm{~s}^{-1}$, respectively.

\section{Acknowledgements}

This work was supported by the National Natural Science Foundation of China (grant nos. 21174011 and U1462102).

\section{References}

[1] Diez-Pascual A M, Naffakh M, Marco C, Gomez-Fatou M A and Ellis G J 2014 Curr. Opin. Solid St. M. 1862 
[2] Pradhan B, Roy S, Srivastava S K and Saxena A 2015 J. Appl. Polym. Sci. 132871

[3] Zhang P P, Zhao X N, Zhang X, Lai Y, Wang X T, Li J F et al 2014 ACS Appl. Mater. Interfaces 67563

[4] Dickson A N, Barry J N, McDonnell K A and Dowling D P 2017 Addit. Manuf. 16146

[5] Duan H Y, Chi W D, Liu Y F, Xing G N, Zhou H, Zou H et al 2014 J. Solid Rocket Technol. 37122

[6] Liu Y F, Chi W D, Duan H Y, Zou H, Yue D M and Zhang L Q 2016 J. Alloys Compd. $\mathbf{6 5 7} 472$

[7] Borda J, Keki S, Rathy I, Bodnar I and Zsuga M 2007 J. Appl. Polym. Sci. 103287

[8] Su Z Q, Li J F, Li Q, Ni T Y and Wei G 2012 Carbon 505605

[9] Ouyang Z F, Li J F, Wang J H, Li Q, Ni T Y, Zhang X Y et al 2013 J. Mater. Chem. B 12415

[10] Su Z Q, Ding J W and Wei G 2014 RSC Adv. 452598

[11] Shit S C and Shah P 2013 Natl. Acad. Sci. Lett. 36355

[12] Tiwari A and Soucek M D (ed) 2014 Concise encyclopedia of high performance silicones (Beverly: Scrivener)

[13] Huang W R (ed.) 2009 Liquid silicone rubber (Chengdu: Sichuan Science \& Technology Press)

[14] Seyedmehdi S A, Zhang H and Zhu J 2012 Appl. Surf. Sci. 258 2972

[15] Siderakis K and Agoris D 2008 Electr. Pow. Syst. Res. 78248

[16] Kim E S, Lee T H, Kim E J and Yoon J S 2012 J. Appl. Polym. Sci. 126 E410

[17] Raquel V, Cristina S A, Javier C G, Fabienne B B, Miguel A R P and Miguel A L M 2008 Eur. Polym. J. 442790
[18] Kulik V M, Boiko A V, Bardakhanov S P, Park H, Chun H H and Lee I 2011 Mater. Sci. Eng. A 5285729

[19] Wang J C and Hao W L 2013 J. Appl. Polym. Sci. 1291852

[20] Bai L and Zheng J P 2016 J. Therm. Anal. Calorim. 1231281

[21] Yue D M, Liu Y F, Shen Z M and Zhang L Q 2006 J. Mater. Sci. 412541

[22] Cao L, Su D F, Su Z Q and Chen X N 2014 Ind. Eng. Chem. Res. $\mathbf{5 3} 2308$

[23] Zhang M F, Zhang G H, Wei G and Su Z Q 2017 J. Mater. Chem. B 51699

[24] Liu Y F, Shen Z M and Yokogawa K 2006 Mater. Res. Bull. 41 1503

[25] Zhdan P A, Grey D and Castle J E 1994 Surf. Interface Anal. 22 290

[26] Ko T H and Li C H 1995 Polym. Composite 16224

[27] Yu M J, Xu Y, Wang C G, Hu X Y, Zhu B, Qiao K et al 2012 J. Appl. Polym. Sci. 1253159

[28] Singh S, Srivastava V K and Prakash R 2013 Mater. Sci. Technol. 291130

[29] Chen Z K, Yang J P, Ni Q Q, Fu S Y and Huang Y G 2009 Polymer $\mathbf{5 0} 4753$

[30] Li Y D, Liu Y F, Zuo Y, Chi W D, Liu B and Shen Z M 2008 J. Mater. Sci. 433738

[31] Pulci G, Tirillo J, Marra F, Fossati F, Bartuli C and Valente T 2010 Compos. A: Appl. Sci. 411483

[32] Schmidt D L 1969 J. Macromol. Sci. Chem. 3327

[33] Liu Y, Ma C, Li Y, Yin Z and Gao Z J 2016 Plast. Rubber Compos. 45430 